\title{
EL SUBSUELO ANÍMICO Y LA LIBERTAD
}

\section{Laura Arias Urízar}

Pontificia Universidad Católica del Perú

laura.malegria@gmail.com

El siguiente trabajo se propone desarrollar la relación entre la vida pasiva del sujeto, y la vida activa del mismo, en el pensamiento de Edmund Husserl. Se centrará sobre todo en el Anexo XII y en la Sección Tercera de Ideas II. Así, luego de describir cómo se constituye la naturaleza material desde una actitud objetivante-teórica, así como la realidad anímica y la diferencia entre el mundo naturalista y personalista, Husserl aborda en qué sentido el sujeto trascendental, visto como persona, se hará cargo, responsable y libremente, de lo constituido.

Palabras clave:

fenomenología, Husserl, constitución, naturaleza material, naturaleza psíquica, mundo cultural, persona, responsabilidad. 
En el presente trabajo nos proponemos desarrollar la relación entre la vida pasiva del sujeto (veremos después en qué sentido "trascendental") y la vida activa (en el sentido de un intellectus agens) del mismo, según Husserl. Nos centraremos, sobre todo, en el Anexo XII de Investigaciones fenomenológicas sobre la constitución' y en la Sección Tercera de la misma obra. Así, luego de explicarnos cómo es que se constituye la naturaleza material, el mundo desde una actitud objetivante (teórica, propia del científico), la realidad anímica, y finalmente la diferencia entre el mundo naturalista y el personalista (actitudes que, veremos luego, podrían mantener referencia entre sí una vez analizado el tema que abordamos en estas páginas), Husserl se dispone a describir en qué sentido el sujeto trascendental ${ }^{2}$, visto ahora como persona, tendrá que hacerse cargo, responsable y libremente, de lo constituido ${ }^{3}$.

Enfocar nuestra atención en estos temas requiere aclarar, de antemano, que nos encontramos ya en la esfera espiritual del yo ${ }^{4}$; esfera en la que se pregunta

\footnotetext{
' Cf. Husserl, Edmund, Ideas relativas a una fenomenología pura y una filosofía fenomenológica. Libro segundo: Investigaciones fenomenológicas sobre la constitución, traducción de Antonio Zirión, México D.F.: UNAM, 1997. Obra que, en adelante, citaremos como Ideas II.

${ }^{2}$ Aquel que "constituye" (aprehende) el mundo en una correlación noético-noemática. Aquel sujeto que se relaciona significativamente con ese su correlato "mundo" y le otorga sentido. Aquel que va más allá de la mera facticidad (aun partiendo de ella) para retrotraerse a esa conciencia

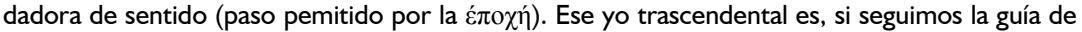
Ideas I, el que constituye en tanto es el responsable de los sentidos constituidos -intersubjetivamente- en la vida activa (tema que nos interesa aquí resaltar dado el enfoque de este trabajo), a "diferencia" (y ponemos entre comillas esto, pues no hay diferencia entre estos "yos" de los que hablamos) del yo fenomenológico que es el que reflexiona sobre esta experiencia dadora de sentido (el que, por tanto, aplica la reducción). Es un yo trascendental que acompaña y se relaciona al mundo de manera "anónima" -pues es la actitud natural la que no sabe de este "ocultamiento"; es la actitud natural la que encuentra al sujeto en el mundo y no al sujeto dirigido al mundo ("para él").

${ }^{3}$ Responsabilidad necesaria en el curso de una filosofía como "ciencia rigurosa" de la que nos habla Husserl. Ciencia que parte de fundamentos últimos, de la propia experiencia y la subjetividad. Hacemos esta equiparación en vistas a lo que explicaremos más adelante con respecto a la responsabilidad que le compete al sujeto. Se trata de hacernos cargo del sentido y validez que damos y encontramos en el mundo.

${ }^{4}$ A diferencia de todo aquel que, siguiendo a Husserl, se encuentra relacionado al mundo de manera "mecánica". El autor muestra claramente aquí su crítica a la postura del naturalismo que reduce toda objetividad a una objetividad natural. Es decir, el "mundo circundante" es visto por este como un mundo circundante natural. Es el mundo de la causalidad natural entendido desde la física moderna ( $y$ su concepción galileana de la naturaleza), medible matemáticamente; en suma, una realidad empírica: en la que la naturaleza, antes de ser interpretada, es "deducida" o, en todo caso, accesible a través de una mera inferencia inductiva. Contra esto, Husserl arguye que el "mundo circundante" no es un mundo natural. Es el correlato de vivencias, correlato de la persona, en tanto son sus vivencias sus comportamientos con respecto a ese mundo (el "ho-
} 
ahora el yo si es capaz de entenderse como ligado a un trasfondo que lo incita, que lo motiva a actuar, decidir, tomar posición, etc., frente al mundo.

Ahora bien, si consideramos que la fenomenología implica un "regresar" a las fuentes de la experiencia misma del mundo, entonces, debemos considerar aquí cómo es que esta experiencia nos habla de intencionalidad. Husserl nos enfrenta a un hecho: $y$ es que la psique tiene intencionalidad (trascendental); es más, es intencionalidad. ¿Qué significa esto? Que somos capaces de constituir al mundo, dice nuestro autor. Proyectamos intencionalmente la mirada hacia el mundo y, de esa manera, lo interpretamos. Interpretarlo implica, así, relacionarnos con él. Esa relación intencional, afirma Husserl, no es fija. Nos relacionamos de diferentes maneras con la objetividad; es esta, pues, una característica de la vida subjetiva. La relación intencional es comportamiento, es un modo de comportarse hacia todo lo que lo rodea: "La conciencia del hombre está abierta directamente a su mundo circundante y esa patencia es posible gracias a que ella se funda en presentaciones que dejan ver ese mundo a través de sí, en tanto estas en cuanto tales permanecen ocultas"5. Con lo dicho, entramos ya al tema a indagar: ver en qué sentido el hombre "despierto" se debe a aquello que, latentemente, como en un "sueño", permite el percibir activo. Así, Husserl nos dice que en el sujeto hay dos tipos de intencionalidad (siendo esta misma una "función"): una que es función consciente, en donde percibo activamente; $y$ otra suerte de intencionalidad pasiva. Esta última es aquella que está antes de la percepción, antes del "yo puedo", del “yo quiero", antes de lo que producimos en lo que llamamos vida consciente. Esta pasividad está dividida, a su vez, en dos: la pasividad primaria (la de los meros impulsos) y la pasividad secundaria (en la que se sedimentan, por ejemplo, tomas de posición pasadas, etc.; y que motivan las actividades volitiva, judicativa, etc.). Hablamos aquí de una intencionalidad pre-egológica.

rizonte de horizontes"). En todo caso, lo natural es lo físico y lo anímico; en interrrelación. Pero es la actitud personalista la que nos interesa, pues vemos cómo a partir de ella se constituye el espíritu (o ámbito de la libertad), a diferencia de la actitud naturalista en la que lo constituido es la naturaleza con sus polos físico-psíquico (alma) y el cósico-físico (cuerpo); y ambas caen bajo el dominio de la actitud natural frente a la fenomenológica (a la que arribamos una vez aplicada la reducción), ante la cual se "dan" (aparecen) el yo natural, el espiritual, etc.

${ }^{5}$ Rosales, Alberto, “Conciencia, vida y cuerpo”, en: La fenomenología en América Latina. Serie filosófica, $\mathrm{N}^{\circ} 3$ (2000), p. 117. 
Husserl nos dice que los sentidos anteriormente constituidos alimentan al yo pasivo secundario y se sedimentan en él a manera de presupuestos, por ejemplo, que no pueden obviarse para el fenomenólogo que aspira a ser un "funcionario de la humanidad". Aquívemos cómo los temas mencionados están en relación con esa actitud fenomenológica que está destinada a "provocar una transformación personal total (...) que alberga en sí el sentido de ser la mayor transformación existencial impuesta como tarea a la humanidad como humanidad"6. De esta manera, la intencionalidad que mencionábamos líneas arriba es aquella que remite a la dimensión trascendental de ese sujeto que se hace responsable del sentido del mundo; responsabilidad a la cual deberían tender todos aquellos que se sepan seres que constituyen sentido. En todo caso, para el tema que nos interesa aquí, el tener que hacerse cargo implica hacerse cargo de los presupuestos de la vida activa (consciente, racional) y de la vida pasiva también. Pero volveremos a este punto una vez analizados estos dos polos: el de la vida activa y el de la vida pasiva.

En este punto, empecemos por ver cómo Husserl describe al yo como un sujeto de actos objetivantes (teóricos, explícitos, "ponentes") y de actos noobjetivantes (actos que, por ejemplo, tienen que ver con los sentimientos, pero que son voluntarios, es decir, pertenecen a la vida racional). Más allá de esto, el sujeto es un sujeto de intencionalidades y de vivencias (pasivas y activas) que actúa en el mundo circundante. Pero no hace únicamente esto, sino que, como mencionamos anteriormente, se debe también a una vida pasiva en la que prima la "sensación". Así, en la vida activa encontramos los actos racionales como los valorativos, los volitivos; pero que no se entenderían como tales sin un subsuelo ( $y$ sin un nexo que relaciona ambos estratos: la percepción, en la que se dan la intuición sensible, presentificaciones, etc.). Este sujeto tiene una mirada activa, es una suerte de percepción consciente que identifica lo que percibe, es el percibir y darme cuenta en la ejecución de un juicio, etc. Aquí la percepción me puede "dar algo" a los ojos -en el transcurso de una vivencia intencional- que puedo luego "elevar" al nivel de lo teórico en sentido fuerte; y así, por ejemplo, aplicar la síntesis categorial (cuando tenemos un juicio, una tesis; tenemos así un acto sintéticamente activo, es

\footnotetext{
${ }^{6}$ Cita de Hua VI, p. I40, en: Hoyos, Guillermo, "La ética fenomenológica y la intersubjetividad", en: La fenomenología en América Latina, p. 130.
} 
decir, síntesis activa, espontánea, discreta que realizamos por la predicación de actos teóricos). En contraposición a esto, tenemos una síntesis estética no espontánea, activa o consciente al nivel de la pasividad (por ejemplo: vemos un vaso $y$, sin darnos cuenta, asociamos ciertos elementos del mismo, teniendo la mirada puesta y enfocada en una característica específica). Se diferencia aquí ese logos como racional de una irracionalidad en la que parece gobernar la intuición sensible. Si hemos introducido aquí esta diferenciación entre actos objetivantes y no-objetivantes, es porque nos servirá para determinar en qué sentido esa "irracionalidad" (ese trasfondo, ese subsuelo, ese "mundo onírico", esa "oscuridad") tendrá mucho qué decir al, por ejemplo, valorar o tomar posición voluntaria ante algún hecho en particular.

El yo del que hablamos aquí es el yo activo, actual, el yo "en vigilia" (que tiene como entorno $y$, por tanto, que se plenifica al llegar a ser "yo hombre"). Como tal, este es el yo que ejecuta, el sum cogitans o "yo pienso" que, como activo, sale "como un rayo" hacia fuera, a través del juzgar, etc. Es el yo que imprime una direccionalidad hacia sus objetividades a través de estos "rayos" o vivencias intencionales. Es este el yo que puede poner coto a sus impulsos o, a veces, dar curso a ellos; en ello radica su libertad. Impera en tanto es libre y funciona a través de sus actos (o vivencias tanto activas -actuales o inactuales-como pasivas).

Pero este yo actual puede pasar a la inactualidad, a la latencia. De este modo, este cogito, siempre en vigilia, puede dar una mirada al ámbito de lo oscuro y convertir esos objetos de la inactualidad como "puestos frente a mí". Esta esfera espiritual de las cogitationes que irradian del yo como actos "(...) tiene su subsuelo en lo 'anímico' inferior y además su teleología inmanente en las transmutaciones legales de lo superior en lo inferior, de lo espiritualmente activo en pasividades, en una sensibilidad secundaria que crea predaciones para las futuras acciones-de-yo, y a la vez caminos delineados de la que hay que llamar propiamente re-producción, de la retransformación en actividades"'. Husserl nos dice aquí cómo el yo actual hunde sus raíces en la esfera anímica de la pasividad. Este yo en la inspectio sui ${ }^{8}$, por ejemplo, puede reflexionar

\footnotetext{
${ }^{7}$ Ideas II, p. 384.

${ }^{8} \mathrm{Cf}$. ibid., § 54. Debemos añadir aquí que Husserl es claro al decirnos que esta autoaprehensión es posterior a la aprehensión que se hace del mundo. El autoconstituirnos (o ser conscientes de
} 
sobre sus experiencias y se aparece a sí mismo de diferentes maneras. Así, se aparece a sí mismo no solo como aquel que actúa, aquel yo individualizado, localizado y temporalizado; sino también como aquel que padece o que en un momento dado se siente "afectado".

Es decir, toda actividad espiritual o actos de yo tienen como característica el ser intencionalidad activa, pero también hay una suerte de estrato en la que se da un mero captar receptivo que, luego, necesitará de esa explicitación de la que es capaz la conciencia. Pero esta intencionalidad personal, como la llama Husserl, siempre apunta a algo (de ahí el que sea teleológica) o puede provenir de algo, de actividades pasadas: "Pues o bien es intencionalidad que nace primigeniamente $y$ es entonces activa, o bien es 'sedimento' de actividades, significativa como tal y en su 'sentido' remitente a los nexos activos o constitutivos, y ello en muchos niveles construidos sobre otros" ". Esta construcción en estratos o niveles es la que nos permite darle la importancia adecuada al substrato primigenio de la pasividad. Este último es el subsuelo del que emergen tomas de posición, actos valorativos; en suma, la espontaneidad de todo acto se encuentra íntimamente entrelazada con un "pasado" o, mejor, conglomerado de experiencias sedimentadas. Este conglomerado es el que permite, por ejemplo, reaccionar ante ciertos hechos similares a los vividos anteriormente de manera, por ende -y esto lo hacemos casi por asociación-, también similar. "Toda espontaneidad se hunde en pasividad, y esto quiere aquí decir: toda objetividad puede ser consciente productivamente de modo primigenio, en su constitución originaria (o en la cuasioriginaria de la reproducción, del recuerdo, de la mera fantasía y semejantes), o puede ser 'sensiblemente' consciente en forma de posconciencia pasiva, que tras el transcurso de la productiva queda a la zaga y permite una mirada retrospectiva (la más primitiva espontaneidad unirradial) al objeto que acaba de ser activamente constituido, o puede asomar un recuerdo o también una transformación de producciones anteriores mediante la eficacia de legalidades anímicas, etc" 10 . Husserl ha querido decirnos que de alguna manera podemos hablar de objetividad a nivel pasivo, si bien no es estrictamente "objetividad",

${ }^{9}$ lbid., p. 385.

${ }^{10} \mathrm{lbid}$. 
se ha dado a la sensibilidad y esta-como potencialidad-puede luego darse a explicitación del cogito que "mira a las profundidades".

Con ello vemos que la pasividad implica, como ya lo hemos dicho, una teleología (en tanto intencionalidad también): tiende a ser esclarecida en tanto es material para el desvelamiento. Todas estas "intencionalidades secundarias" tienden a una renovación, a una re-producción o a una conversión en actos espontáneos, dice Husserl. Así: "La conciencia, como intencionalidad organizada, operante, ha tenido una protohistoria de impulsos intersubjetivos que alcanzaron su meta y que funciona como condición" ". Con lo que entendemos que es desde este subsuelo anímico que arranca el desarrollo de la persona de la cual hablábamos anteriormente. Es desde esta génesis pasiva que el yo concreto se ve a sí mismo como tal, como "hombre despierto", pero sin dejar de lado que él mismo, como espíritu, "tiene un subsuelo anímico"12. Es un yo vigilante en tanto conciencia en un modo actual, pero que se percata del hecho de que, aun estando en una percepción que se presenta como "clara", no puede evitar cierta "indeterminación". Esta última es la que le pertenece a todo aquello que se nos da en la experiencia, "todo aquello que nos es dado de esta manera, se ofrece en un horizonte brumoso; está rodeado por un horizonte obscuramente consciente de realidad indeterminada y constituye globalmente nuestro mundo de la percepción"'3. Ahora bien, esta indeterminación no se queda allí, es decir, Husserl nos dice que ella es susceptible de ser determinada o, mejor dicho, esclarecida.

En ese sentido, toda percepción oscura entraña la posibilidad de convertirse en actual, con lo cual no estamos diciendo otra cosa que el curso de toda vivencia está caracterizado por una incesante modificación atencional. Lo que rescatamos aquí es que todo aquello que no aparece claramente en una dación es lo no percibido, pero que permanece como co-dado, como co-presente.

\footnotetext{
" Iribarne, Julia, "La cuestión de la libertad en el pensamiento de Husserl", en: Rizo-Patrón (ed.), El pensamiento de Husserl en la reflexión filosófica contemporánea, Lima: PUCP/IRA, I993, p. 7. En donde la autora también nos dice: "En la medida que el proto-yo 'habita' su cuerpo vivido, ejercita la experiencia que encarna, en el nivel más primario, el significado de la libertad. Se trata de la experiencia muda del 'puedo moverme', comienzo de una historia de sedimentaciones que culminan en la configuración del yo concreto".

12 Ideas II, p. 385.

${ }^{13}$ Jaramillo, Mónica, "La evolución de la idea del inconsciente en la fenomenología de Husserl”, en: La fenomenología en América Latina, p. 262.
} 
Esto es lo que posibilita el que la conciencia admita una inactualidad que, en lugar de ser "nada", permita la emergencia de "algo". Esa oscuridad es, pues, subsuelo. "Las vivencias anteriores < las sedimentadas> no desaparecen sin dejar huella; cada una tiene sus repercusiones"14. Entonces podemos volver sobre una vivencia que permanece, ahora, oculta y esclarecer el nivel de vivencias actuales sucesivamente. Todo aquello que en algún momento fue consciente, puede ser sacado a la luz y, así, pasar de una suerte de potencialidad a una suerte de actividad. Esa actividad es la del intelecto agens que está en constante "vigilia".

Así pues, todo aquello que hemos llamado "oscuro" es oscuridad que en un momento fue luz; este es un pre-nivel, el nivel del pre-yo que se volverá intencionalidad activa y consciente, pero que fue intencionalidad pasiva e involuntaria, "receptiva". Es un mundo originario, suelo primordial de experiencia receptiva en donde se instala la preconstitución y la unidad de lo pre-dado. "Distinguimos aquí sensibilidad y (decimos) razón. En la sensibilidad distinguimos la protosensibilidad, que no contiene nada de sedimentos de la razón, y la sensibilidad secundaria, que nace de una producción de la razón. En conformidad con ello dividimos también la razón en razón primigenia, intellectus agens y razón sumergida en sensibilidad"15.

Hemos mencionado aquí el tema de la "receptividad", de la "afección"; ello ha sido porque nos remiten al tema de la sensibilidad, que es el que nos interesa para esclarecer la cuestión del subsuelo anímico. Así pues, este subsuelo es llamado por Husserl la "protosensibilidad" como unidad anterior a cualquier apercepción. En la primera se dan los impulsos en tanto protovivencias y, estos, están regidos por ciertas leyes no emanadas de la razón. Por ejemplo, nos encontramos con la mera asociación y la reproducción. Pero, más allá de esto, retomemos el tema del yo y la sensibilidad. Esta, dice Husserl, es presupuesta por el yo como afección, como estímulo; así, en esta esfera de la intencionalidad impropia, la receptividad es espontaneidad ínfima (de esta receptividad, en el ámbito de lo sensible, surge, por ejemplo, el espacio). En este sentido, "la receptividad es el acto del yo de atraer a sí lo que le es

\footnotetext{
${ }^{14}$ Ibid., p. 264.

${ }^{15}$ Ideas II, p. 386.
} 
pre-dado a través de los estímulos que lo afectan"16 (por tanto, no es esta receptividad capacidad puramente pasiva, sino que en esta receptividad se encuentra ya un grado, aunque inferior, de actividad ${ }^{17}$ ). Esto no es otra cosa que la pasividad secundaria, experiencia receptiva previa a toda explicitación en donde, de alguna manera, tenemos al mundo como pre-constituido.

La conciencia, el estado de la vigilia, necesita recoger todo pasado (hacerse cargo de él) como presupuesto subyacente y proyectarse, así, hacia un futuro, hacia posibilidades (sentido protencional), hacia una constitución de nuevas objetividades del ego-cogito. Pero antes de hablar de este "despertar", de este "abrir los ojos", sigamos viendo en qué sentido lo sedimentado, el "yo dormido", motiva una acción, una actividad consciente. Es necesaria esta oscuridad ( $y$ hablamos aquí no solo de la pasividad secundaria -en la cual se forjan actos valorativos, etc.-, sino de la primaria -impulsiva), y es necesario que ella se desoculte, pero no constante o permanentemente: "Un ser finito solo puede tener conciencia de su mundo circundante, si él mismo permanece oculto para su conciencia en diversos grados de latencia, de suerte que lo así guardado puede en algunos casos hacerse patente, mientras que en otros permanece siempre oculto (...) Además, sería imposible percibir y actuar sobre los entes circundantes con la atención necesaria, si estuviéramos a la vez expresamente conscientes del funcionamiento vegetativo de nuestros órganos corporales"18. Estamos, así, ante un proceso de ocultamiento y desocultamiento necesario para el sujeto, para el yo-hombre que se relaciona a su mundo circundante: “(...) diferentes cosas pueden ser llevadas unas tras otras al núcleo de presencia privilegiada, pero no al mismo tiempo. Cuando unas experimentan un proceso de presentación, otras deben quedar sujetas a un proceso de despresentación"'9.

Esta latencia es condición necesaria para la conciencia, para el "yo pienso". Es de esta manera que lo oculto, el subsuelo (el, podemos llamarlo así, preconocimiento) está relacionado con la patencia de la conciencia. Esa conciencia

\footnotetext{
${ }^{16}$ Jaramillo, Mónica, op. cit., p. 267.

${ }_{17}$ Y esto porque la percepción es una vivencia, a su vez, constituida a partir del subsuelo previo del flujo de sensaciones.

${ }^{18}$ Rosales, Alberto, op. cit., pp. II 0 - III.

${ }^{19}$ Walton, Roberto, “Horizonticidad y trascendentalidad”, en: Rizo-Patrón, Rosemary (ed.), op. cit., p. 138.
} 
esclarece y "eleva" los contenidos y vivencias pre-reflexivas en tanto las explicita y, en tal sentido, aplica un análisis intencional de los mismos. Será el yo trascendental el que incluya todas esas potencialidades del trasfondo en tanto las reconoce como reflejo de sus propias capacidades ${ }^{20}$. Esta conciencia "iluminadora" se ve motivada y reacciona ante ciertos estímulos provocados por la oscuridad y el trasfondo anímico. Y es que la asociación (casi mecánica) que se da en las vivencias proto-intencionales motiva y alimenta, a su vez, la motivación del nivel objetivante, es decir, motiva el trabajo de la conciencia intencional en tanto le dona los contenidos guardados para reconocer tal o cual situación específica. Sin ese trasfondo, el caer en el error sería más recurrente ( $y$ no por ello decimos que el error deba erradicarse, pues es imposible; es, más bien, necesario que se dé) y no habría la capacidad de esclarecer contextos en los cuales se requiera de ciertas disposiciones para llegar a una resolución. Hay, pues, una ligazón necesaria entre la costumbre y aquello que llamamos "libertad". Somos libres de elegir si es que podemos discernir frente a lo que se nos da. Lo sedimentado permite el desarrollo de capacidades y disposiciones, lo sedimentado tiende a "elevarse" a la conciencia de la cual es condición. Lo sedimentado, entonces, está estrechamente entrelazado con el ámbito de la libertad (tema que tocaremos líneas posteriores).

Todas las vivencias están motivadas porque en el nivel primario pasivo hay una síntesis temporal (es el curso sintético temporal caracterizado como profundidad de la experiencia no determinable de manera puntual); este modo de síntesis motiva el que tengamos cierto tipo de vivencias en el nivel activo (aunque no sepamos el origen $)^{21}$. Y esta motivación no solo se reduce a este ámbito. Ella también se encuentra al nivel de la empatía y de la intersubjetividad, en tanto el mundo espiritual/social motiva en nosotros un nexo con el entorno. Pero esto, dice nuestro autor, no debe confundirse con una reducción naturalista en la explicación del comportamiento humano. Así, no se trata de una motivación de leyes meramente físicas, causales y deterministas. Recordemos que la pregunta clave para Husserl, con respecto a este tema, es aquella que apunta a la libertad en el sujeto en tanto voluntad actuante, posicionante, responsable, etc. Se desprende de lo expuesto que la percepción es el nexo entre la vida

\footnotetext{
${ }^{20}$ Cf. ibid., p. 135.

${ }^{21} \mathrm{Cf}$. Ideas II, § 56 .
} 
pasiva y la activa. Pero ello no significa que porque el mundo se me da perceptivamente, se encuentre algo, por debajo o detrás de este, que tenga que explicitar o convertir a lenguaje científico-matemático (el físico como aquel que ve "adecuadamente" el mundo). La motivación no debe ser confundida, por tanto, con la causalidad de lo cósico. La motivación nos habla, más bien, de cómo están enlazadas las vivencias en relación a noemas o unidades de sentido. Se trata, una vez más, de intencionalidad. El sentido es, entonces, el correlato de la vida del espíritu a la cual nos hemos abocado aquíi ${ }^{2}$.

Ahora bien, esta motivación es la que nos remite, cuando hablamos del yo como sujeto de las capacidades ${ }^{23}$, a la dimensión de la sedimentación no solo como habitualidad, sino que allí hay capacidades fruto de un desarrollo personal. Lo que importa aquí es que hay una historia individual de la persona. En todo caso, el hábito, en su origen, puede haber sido algo activo, una decisión, un volverse tal, etc.; pero ser un organismo de capacidades quiere decir que también las sedimentaciones nos permiten desarrollar potencialidades, disposiciones personales. No todo es mero hábito, hay libertad que está entretejida con el hábito: esto es la capacidad (además, hay proto-capacidades). El sujeto está "atado", de alguna manera -ínfima-, a la naturaleza mecánica, sí, pero también hay una combinación y juego con la libertad que posee de elegir por tal o cual disposición. "Todo espíritu tiene algo de 'naturaleza'. Este es precisamente el subsuelo de la subjetividad, su consciente tener sensaciones, su tener reproducciones de sensación, sus asociaciones, su formación de apercepciones, y en verdad de las más bajas, las que constituyen unidades de experiencia" ${ }^{24}$. Pero no entendamos aquí naturaleza en sentido determinista, pues Husserl nos dice que hay impulsos a los cuales se les puede poner coto (como no); esta capacidad es la que muestra y hace patente la libertad del sujeto. Añade Husserl: "los espíritus son sujetos que ejecutan cogitationes, las cuales se hallan sobre este subsuelo y están entrelazadas en nexos más abarcantes, en los cuales imperan motivaciones en sentido superior -motivaciones de tomas de posición por tomas de posición, motivaciones de razón propiamente

\footnotetext{
${ }^{22}$ La intuición capta más que mero cuerpo físico desconectado. Hay un plus, un excedente en la intuición sensible; un "en tanto que" apofántico.

${ }^{23}$ Cf. ibid., § 59 .

${ }^{24}$ Ibid., p. 327.
} 
dichas" 25 . Hay, en suma, sensaciones y reproducciones que "tienden a" y, a su vez, afecciones hacia el sujeto como tendencias a la captación (tendencias de deseo, sensaciones de placer o displacer, etc.).

Toda tendencia está dirigida, dice nuestro autor, a un objeto intencional que motiva y aparece como impulso. Pero dijimos que había motivación en tanto afección. Esto no es excluyente con el hecho de que no toda actividad del yo es mero ceder. No somos mera receptividad, afección y pasividad: este nivel es el inferior comparado al de los nuevos actos, los actos libres, "las actividades del yo propiamente dichas, el libre tomar posición frente a las afecciones, en vez de una condescendencia ya pasivamente ejecutada como un desaprobarlas, etc. Entonces, eventualmente el ceder puede ser a la postre un ceder libre" 26 .

Este es el yo personal que estaba determinado por la vida pasiva, pero que también es un yo libre de costumbres. La actividad del yo, el estado de vigilia del mismo, están vinculados a la libertad que hay en él (no estamos, por tanto, únicamente en conexión con la naturaleza, desde la pasividad, primariamente hablando). Esta libertad es la del resolverse. Así, descubrimos que hay una motivación libre racional y otra motivación por costumbre. En esta última no se toma una decisión, se hacen las cosas automáticamente. En el primer caso, la motivación del yo activo "no se origina por 'asociación' y por 'legalidad psicofísica', o sea, no se origina como lo hacen todas las formaciones de la sensibilidad. Está presupuesto, sin embargo, el engranaje entero de la naturaleza, el 'mecanismo de la naturaleza'" 27 . De esta manera, el yo de la libertad no puede estar anexado a la naturaleza de manera mecánica; pues "mera naturaleza es todo 'yo hago mecánico"”28. Lo que afecta al yo, llega a él, pero no al yo despierto o en vigilia. Se convierte, así, en experiencia que se sedimenta y vuelve a resurgir en ocasiones posteriores o de índole similar. Dice Husserl: "El yo vive siempre en el medio de su historia, todas sus anteriores

\footnotetext{
${ }^{25} \mathrm{lbid}$.

${ }^{26}$ Ibid., p. 390.

${ }^{27} \mathrm{lbid}$.

${ }^{28} \mathrm{lbid}$. Y aquí Husserl introduce el ejemplo de estar fumando un cigarrillo mientras se está atento a "otra" actividad y la cuestión de las actividades del yo en simultaneidad (y, por ello mismo, queda una de las vivencias como no esclarecida del todo) con ciertos comportamientos no absolutamente conscientes. Tenemos en este ejemplo la afección del yo y reacciones "inconscientes".
} 
vivacidades están hundidas y repercuten en tendencias, en ocurrencias, transformaciones o similaridades de anteriores vivacidades, nuevas formaciones fusionadas a partir de esas similaridades, etc. -enteramente como en la esfera de la protosensibilidad, cuyas formas también pertenecen al medio del yo, a su haber actual y potencial”29.

En el $\S 60$ de Ideas II, Husserl define a la persona como un sujeto de actos de razón, como un yo "libre”. ¿Qué implica esto? ¿Qué significa? Que el sujeto racional, en tanto libre, es responsable. Es un "yo puedo", un "yo consciente", el "yo puedo" de la voluntad. Y la voluntad nos remite a la tesis activa del arbitrio. Lo que cae en mi dominio, lo prácticamente posible es, pues, el dominio de la libertad. En contraposición, la vida pasiva (primaria) es caracterizada como el dominio impulsivo, pero previo a la voluntad (y decimos "previo" en tanto condición de posibilidad). Aquí encontramos al "yo me muevo", por ejemplo ${ }^{30}$, que se contrapone al "yo puedo". Pero no olvidemos que esto no significa que Husserl considere a estos dos ámbitos como separados. Más bien, están en estrecha vinculación; así por ejemplo, podríamos bien decir que el ámbito espiritual presupone el físico, incluso el psico-físico. Y ya hemos mencionado en qué sentido toda actividad intencional o protointencional se debe al dominio natural (aun en un grado ínfimo) ${ }^{31}$. Lo espiritual y lo natural están en íntima relación, pero no son lo mismo. Más bien, podemos leer una suerte de modos motivados de relacionarse con las cosas ( $y$ a esto se añade el que esa motivación sea llevada a cabo a través de la intencionalidad teleológica).

En este sentido, las explicaciones sobre la relación del sujeto con el hombre, en esa relación constitutiva de sentido, no puede ser de orden naturalista $\circ$ puramente causal. El avance se da abordando a la persona como teniendo

\footnotetext{
${ }^{29}$ Ibid., p. 39I.

${ }^{30}$ Aquí Husserl introduce la diferencia entre el "yo puedo lógico" y el "yo puedo práctico". En donde mis capacidades se ven absolutamente ligadas a mi corporeidad. $Y$ es que mi cuerpo es un límite para toda actividad, en tanto él me permite y me imposibilita ante ciertos actos. Así, hay "algo" que nos permite traducir nuestro "querer" en una actividad físico-corporal; es decir, reconocemos una suerte de causalidad en la voluntad, una relación entre dos ámbitos que, a la par, se vinculan entre sí (por ejemplo, desde la "motivación", la "afección", etc.): el ámbito de la naturaleza -donde se encuentra lo físico y lo fisiológico-, y el ámbito espriritual, propiamente dicho, como el ámbito del "yo puedo" y el "yo consciente". Cf. ibid., § 60, p. 306.

${ }^{31}$ Cf. ibid., p. 308. Aquí el autor nos explica cómo, por ejemplo, el "yo quiero mover algo" se plenifica como tal únicamente si es que hay una capacidad previsora de levantar un peso. Y esto solo por poner un ejemplo; el movimiento es explicable en términos físicos (incluso fisiológicos).
} 
capacidades, disposiciones y decisiones forjadas desde una vida pasiva (es decir, hablamos también aquí de "anticipaciones"). Esta última es aquella en donde se funde la actividad del sujeto para volverse hacia el mundo y su aprehensión ${ }^{32}$. Pero este grado de motivación llega a un nivel, por decirlo así, "superior" en tanto se convierte en acto de un yo de motivación, a diferencia de un yo de experiencia del nivel de la vida pasiva. Esta experiencia es la que, luego, enlazada a la vida activa, nos entrega la posibilidad de disponernos de tal o cuál manera ${ }^{33}$. Estas experiencias, entrelazadas con la vida activa, muestran la libertad del sujeto cuando no cede simplemente a las exigencias ajenas o a los propios impulsos. La persona es, pues, sujeto de actos de razón, en el sentido que constituye la vida libre, el acto ${ }^{34}$.

El ser humano se presenta, entonces ( $y$ esto interpretando el § 61), como una mezcla entre aquello que llamamos "naturaleza" y "libertad". Sin tomar en cuenta la comprensión del desarrollo del hombre como ligado a un subsuelo, caemos en una explicación meramente psico-física. El desarrollo de este hombre se da desde esta vida pasiva (la primaria y la secundaria, pues está estratificada). Es en ese trasfondo que está supuesto el ámbito físico de la corporeidad, el ámbito fisiológico y el ámbito psíquico. Su subjetividad está conformada por dos grandes niveles (lo que nos permite entenderlo como una doble subjetividad): por un lado, la vida activa "superior", el cogito de las valoraciones, el yo espiritual activo, "despierto", siempre "en vigilia”, intellectus

\footnotetext{
${ }^{32}$ Cf. ibid., p. 313 .

${ }^{33}$ Cf. ibid., p. 268. Husserl introduce aquí el tema de la "resolución", junto al cual se dice que hay motivaciones que se validan por valores. $Y$, de entre ellos, hay valores que tienen mayor fuerza que otros, por tanto, tienen como resultado vivencias más fuertes, etc. Este sería el caso, por ejemplo, de las motivaciones personales, en las que puede darse el caso de la influencia de una personalidad por otros yos. El punto es que esa misma persona actúa de maneras diferentes ante las mismas circunstancias. No se trata, entonces, de una mera deducción "a iguales circunstancias, iguales reacciones". Si las tomas de posición se sedimentan, ellas luego pueden ser reevaluadas, traidas a la vida presente de nuevo para tomar así una postura diferente, por poner un ejemplo. ${ }^{34}$ Persona que no debe confundirse con la persona humana que es unidad perceptiva que se capta en la percepción de sí misma y de otros; "con otros", diría el propio Husserl. Cf. ibid., pp. 316317. Asimismo, si las cosas son comprensibles por una suerte de "tipicidad" general, lo mismo no ocurre en el caso de las personas. Ellas tienen un trasfondo personal que se constituye como carácter típico a través de experiencias que se han dado continuamente. Hay, entonces, algo así como una tipología distinta para cada vida personal. En esto radica el conectarse intersubjetivamente, sí, desde una dimensión interior de la intracomprensión como sujetos de motivación, por niveles de comprensión del otro, etc.; pero que, en ningún caso, debe entenderse como una mera causalidad. Cf. ibid., p. 317.
} 
agens. Este es el yo de los actos libres, de la razón. Y, por otro lado, este mismo yo puede mostrar a un yo no-libre que se manifiesta por la sensibilidad pasiva, el yo de la oscuridad, del subsuelo anímico. Pero si retomamos la idea de la intencionalidad teleológica, y considerando también la teleología de la vida de los sujetos, entonces, tenemos una subjetividad pasiva que "tiende" siempre a presentarse. Es una tendencia de las latencias -inherentes a la vida activa- hacia las formas más "elevadas" de razón.

Ahora bien, hacerse cargo de esos impulsos y hacerlos caer bajo el dominio de la voluntad nos entrega un sujeto o una conciencia responsable. Veremos en qué sentido esta responsabilidad es a la que nos llama nuestra propia vida pasiva, dice Husserl. Sin que esto signifique, como dijéramos líneas arriba, que todas las formas oscuras se conviertan en reflexión total (pues, según afirma el autor, no hay posibilidad de una reflexión total). Hay un transfondo que tiene que permanecer oscuro; de otro modo, nuestra intencionalidad no podría entenderse como teleológica, como tendiendo siempre a plenificarse.

El elemento del inconsciente aparece entretejido en el consciente. Todo lo que se da en la vida consciente es ya síntoma de lo que pasa en la vida inconsciente. Por tanto, creemos que Husserl nos aclara que no hay una fractura total entre estos dos ámbitos. Yno la puede haber, por las razones ya explicadas. Además, la percepción, tal y como ha sido descrita, parece erigirse como el nexo o puente entre uno y otro ámbito. Ella es la frontera, el dominio intermedio, en donde están "presentes" estos dos mundos. Aun así, esta percepción no es responsabilidad total. En este nivel no hay sometimiento a la voluntad (y, por ello, en el nivel de la percepción, puedo también "desviarme", se admite aquí la posibilidad del error). Más bien, los impulsos ciegos no nos dejan entrever una toma de posición absoluta o desprovista de ellos. La vida consciente explicita, pero iqué es lo que explicita? Pues aquello que luego el sujeto intenta reconstruir: el subsuelo anímico a la base de su actividad. De esta manera, no hay una conciencia "separada". El yo personal, ya como sujeto que destaca de entre "las profundidades", tiene propiedades y comportamientos aquiridos en la vida, que forman parte de su "estilo" y que tienen un trasfondo oscuro (ante el cual nos podemos ver tentados $y$, es más, ceder). 
Dice Husserl que el yo actual se entrelaza al potencial, pues toda vida activa, "todo ello tiene su curso de naturaleza, por ende, incluso todo acto libre tiene su cola de cometa en la naturaleza: pero él mismo no ha llegado a ser a partir de la naturaleza (nacido por la mera legalidad de la naturaleza), sino que precisamente ha llegado a ser por el yo; yo y naturaleza son contrastes, y todo acto tiene también su lado de naturaleza, esto es, su subsuelo de naturaleza: lo que está predado afectando, es formación de la naturaleza, aunque también aquí y allá puede haber coactuado algo yoico en la acción anterior. Y todo acto tiene su lado de naturaleza, principalmente en la ejecución de actos similares anteriores, y lleva consigo una tendencia asociativa, una tendencia de naturaleza, a ejecutarlo de nuevo (...)"35.

Ante esta pasividad, ante este ceder a los impulsos es necesario el "abrir de ojos", el "despertar del sueño" para alcanzar el telos de patencia. Sin que esto implique un olvido de la previa experiencia retencional: "Un pasado olvidado me viene súbitamente al espíritu; la idea hace irrupción fuera de lo que se llama el inconsciente en el cual lo que es consciente en el sentido específico del desasimiento particular es una simple isla" ${ }^{36}$. El dominio pasivo, el del sueño, puede ser entonces despertado de nuevo. El inconsciente es así "esa vitalidad nula de la conciencia que no por ello ha de ser considerada fenomenológicamente como una nada inerte, sino como un modo límite de la conciencia" ${ }^{37}$. Todo acto, al fin y al cabo, es fundado en la vida pasiva; es -siguiendo a Husserl- re-acto. Pues el acto no es otra cosa que la presentación, la plenificación de ciertas convicciones que se han instalado en el yo y que van regulando su hexis, en vistas a convertirse en ese "yo puedo", en sujeto de voluntad. "Cuando el yo accede a la forma más alta de organización deviene persona, de ella es posible afirmar que 'es libre, que se decide como se decide, pero también puede decidirse de otro modo'"38.

El yo personal es libre, es cogito y toma en consideración todo aquello que en su vida activa se le presenta como posible. Como tal, observa aquellas

\footnotetext{
35 Ibid., p. 391.

${ }^{36}$ Husserl, Edmund, “De la síntesis pasiva”, en: Hua XI, Apéndice X, p. 368. Citado en: Jaramillo, Mónica, op. cit., p. 27I.

${ }^{37}$ Husserl, Edmund, ibid., p. 409; citado en: ibid., p. 272.

${ }^{38}$ Iribarne, Julia, op. cit., p. 8.
} 
posibilidades y les da forma, les da curso si es que así lo exige la situación particular. No se trata de seguir al mero "yo deseo", sino de examinarlo y dar cuenta de su posibilidad de actualización una vez esclarecidas las circunstancias que rodean al yo personal: “(...) reconozco que es posible ser de otro modo, yo mismo en mis habitualidades persistentes estoy en mi poder, tengo poder sobre mí mismo, me determino a mí mismo prácticamente, soy resultado de mis obras" ${ }^{39}$, en ese sentido soy libre también.

Se trata de "abrir lo ojos", pues debemos asumir lo que somos y cómo nos forjamos en tanto seres responsables de la relación con los otros y para los otros. Aparece el tema de la intersubjetividad que no desarrrollaremos aquí, pero que se encuentra entrelazado o traslapado en todos los escritos de Husserl, y al cual tiende el tema que hemos escogido. En todo caso, la vida pasiva es la que nos impulsa a actuar, desde ella podemos preguntarnos por el actuar, por el cómo debemos actuar, así: "esta pregunta emerge a partir de la noche del olvido; que parece surgir del más profundo fondo del abismo. De un abismo que es preciso reconocer cómo se incorpora una sombra; es decir, volviendo los ojos hacia nuestra propia existencia oscura y crepuscular antes de decretar la existencia de los otros"40.

Esta libertad tiene como telos la elección personal que debe concretarse a un nivel "superior", pero que es motivada, impulsada por una oscuridad previa. Se trata de un ir y venir de la conciencia a su subsuelo. La persona, como libre, es "sujeto social que aspira y se esfuerza por ser fiel a sí misma en el desarrollo responsable de su 'alma germinal'. Está tensada por los carriles performativos de las habitualidades y creencias, por una parte, y por otra, por los carriles de la realización de lo 'superior'. El funcionamiento consolidado en hábito se muestra como lo asumido por el sujeto a la manera de un estilo tradicional"4l.

Esta responsabilidad de la que nos habla Husserl no puede escindirse del interés por el otro. Así, la libertad se funde en la intersubjetividad, en reconocer que somos seres en relación y que toda convicción implica una autovaloración y

\footnotetext{
${ }^{39} \mathrm{lbid} .$, p. 13.

${ }^{40}$ Jaramillo, Mónica, op. cit., p. 272.

${ }^{41}$ Iribarne, Julia, op. cit., p. 19.
} 
proyección en el otro como polo intersubjetivo. Esta capacidad de reconocerse como libre en el hombre no debe permanecer en la esfera particular, individual. Más bien, es un reconocimiento de la vida libre del sujeto que obliga a este a confrontar al otro, y así, enfrentarse a sí mismo. Mi voluntad me dice que el otro está allí para ser satisfecho, para ser visto y comprendido, para ser coaprehendido en términos de voluntad también. No existe un "choque" entre ambos, sino más bien un estar con el otro y para el otro. Se trata de despertar y asumir estas convicciones como tales y como posibles de ser proyectadas, actualizadas en un horizonte que está conformado por el otro. Este otro, a su vez, me plantea una conexión y vinculación que no puedo negar. En el engranaje de las vivencias, nos co-pertenecemos. El sentido de la responsabilidad no se da solo a nivel individual, sino social; allí es donde encontramos al sujeto trascendental como intencionalidad que se vuelca sobre el sentido de un co-constituirse. Vemos que este responsabilizarse se dirige a los fines de la "humanidad"; así, dice Husserl sobre el hombre como ser personal y libre: "Como punto de partida tomamos la facultad propia de la esencia del hombre, la autoconciencia en el sentido preciso de autoinspección personal (inspectio sui) y de la facultad, fundada en la inspectio sui, de tomar posición reflexivamente acerca de sí mismo y de su vida y de actuar personalmente: autoconocimiento, autovaloración y autodeterminación práctica (autovolición y autoconstitución). Con base en la inspectio sui es consciente el hombre no solo de su libertad, sino también del horizonte en el que se inscriben sus consideraciones críticas y sus valoraciones: pertenece a la esencia del hombre ejercer su representar, pensar, valorar y querer no como actos singulares, sino que puede realizar todos estos actos también en las formas de lo absoluto, en aquellas de la generalidad 'particular' o 'universal'" ${ }^{\prime 42}$. De esta manera, la responsabilidad es no solo personal, sino social. Y como tal, evidencia la teleología de la intencionalidad de la razón que no es otra cosa que el "ten62 der siempre hacia". La libertad en el hombre implica un hacerse cargo de los sentidos y del surgimiento de los mismos ( $y$ la tendencia de estos hacia fines cada vez mayores), así, de la vida actual, pero que permanece entrelazada con ese ámbito de oscuridad al cual debemos volvernos en tanto seres de reflexión, autocomprensión, autorreflexión (inacabada), etc. "El espíritu no es un yo abstracto de los actos que toman posición, sino que es la personalidad

${ }^{42}$ Hoyos, Guillermo, op. cit., p. 136. 
plena, yo-hombre, el yo tomo posición, el yo pienso, yo valoro, actúo, llevo a cabo obras, etc. (...) Y me co-pertenece luego un subsuelo de vivencias y un subsuelo de naturaleza ('mi naturaleza') que se manifiesta en el engranaje de las vivencias" ${ }^{\prime 3}$. 